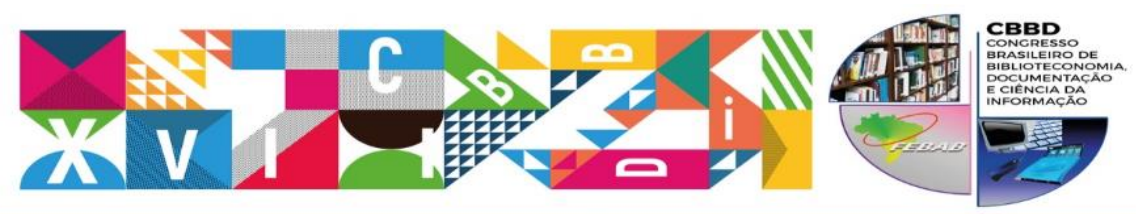

XXVII CONGRESSO BRASILEIRO DE BIBLIOTECONOMIA, DOCUMENTAÇÃ̃O E CIÊNCIA DA INFORMAÇÃO

TEMA CENIPAl: Objetivos para o Desenvolvimento Sustentável das Naçōes Unidas:
como as bibliotecas podem contribuir com a implementaçăo da Agenda 2030

\title{
POLÍTICAS DE INCLUSÃO DE ACESSIBIILIDADE PARA A PROMOÇÃO DA COMPETÊNCIA EM INFORMAÇÃO: um olhar para a Biblioteca Central da UFMS
}

\section{Lilian Aguilar Teixeira}

Bibliotecária na Universidade Federal do Mato Grosso do Sul.

E-mail: $\underline{\text { lilian.teixeira@ufms.br }}$

\section{Tânia Regina de Brito}

Bibliotecária na Universidade Federal do Mato Grosso do Sul.

E-mail: tania.brito@ufms.br

Jaziel Vasconcelos Dorneles

Bibliotecário na Universidade Federal do Mato Grosso do Sul.

E-mail: jaziel.dorneles@ufms.br

\section{Rogério Ferreira Marques}

Bibliotecário na Universidade Federal da Paraíba. E-mail:

rogeriomarques@ci.ufpb.br

\section{RESUMO}

Aborda questões de acessibilidade de pessoas com deficiência na Biblioteca Central da Universidade Federal de Mato Grosso do Sul (UFMS), realiza um levantamento das políticas existentes no Brasil, com um check list considerando como referência a NBR 9050/2015, visando identificar o que está implantado na biblioteca. Faz uma reflexão sobre como o atendimento à lei pode contribuir para a promoção da competência em informação. Os resultados apontam que deve existir uma parceria da biblioteca com a Divisão de Acessibilidade e Ações Afirmativas (DIAAF) e que algumas adequações devem ser realizadas para permitir que as pessoas com deficiência realizem seus estudos e pesquisas com maior autonomia e independência.

Palavras-chave: Acessibilidade. Biblioteca Universitária. Competência em Informação. Pessoas com deficiência.

\section{ACCESSIBILITY AND INCLUSION POLICIES FOR PROMOTION OF INFORMATION LITERACY: a look at UFMS Central Library}

\section{ABSTRACT}

It approachs disabled people accessibility in Central Library of Federal University of Mato Grosso do Sul (UFMS), creating a data collection about existent policies in Brazil, with a checklist considering as reference the NBR 9050/ 2015, looking to identify what is already implanted in the library. It makes a reflection about how the law attendance can contribute for a promotion of information literacy. The results point that may exist a partnership of library with the Acessibility and Affirmative Actions Division (DIAAF) and that some adjustments may be realized, so disabled people 


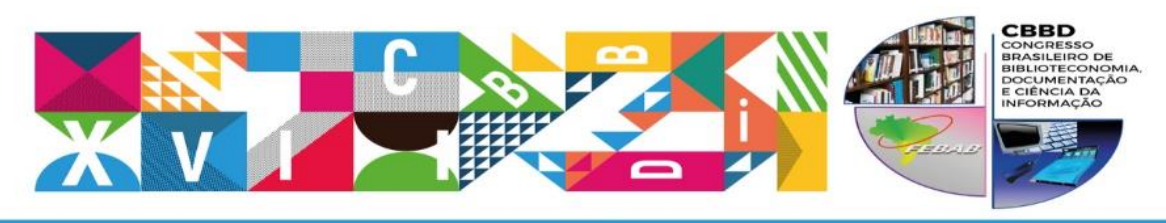

XXVII CONGRESSO BRASILEIRO DE BIBLIOTECONOMIA, DOCUMENTAÇÃ̃O E CIÊNCIA DA INFORMAÇÃO

TEMA cENIRAL : Objetivos para o Desenvolvimento Sustentável das Naçōes Unidas:
como as bibliotecas podem contribuir com a implementaçao da Agenda 2030

can accomplish their studies and researches with bigger autonomy and independence.

Keywords: Accessibility. University Library. Information Literacy. Disabled People

\section{INTRODUÇÃO}

A política de inclusão das pessoas com deficiência no Brasil existe desde a Constituição de 1988. Desde então, inúmeras leis, decretos e normas foram criados para regulamentar, integrar e promover a igualdade e a acessibilidade das pessoas com deficiência ou com mobilidade reduzida. Mas é a Lei no 13.146 de 6 de julho de 2015 que institui a Lei Brasileira de Inclusão da Pessoa com Deficiência, conhecida também como o Estatuto da Pessoa com Deficiência, a qual foi "[...] destinada a assegurar e a promover, em condições de igualdade, o exercício dos direitos e das liberdades fundamentais por pessoa com deficiência, visando à sua inclusão social e cidadania." (BRASIL, 2015, art. 1ํㅜ p. 2). A importância desta Lei se traduz na consolidação dos avanços trazidos pelas regulamentações anteriores, e estabelece novos direitos às pessoas com deficiências.

Desde 2013 a Universidade Federal de Mato Grosso do Sul (UFMS) vem planejando ações que foram implementadas pelo Plano de Desenvolvimento Institucional (PDI) 20152019, que instituiu políticas de acessibilidade que garantissem aos alunos o ingresso, a permanência e conclusão dos seus cursos de graduação e de pós-graduação. Tais políticas abrangem estudantes com "[...] impedimento físico, sensorial, mental/intelectual, deficiências múltiplas, transtornos mentais, bem como aqueles com altas habilidades/superdotação". (UFMS, 2016, p. 214).

Dentre as 11 diretrizes gerais para as políticas de inclusão da UFMS, uma delas contempla a "adequação das bibliotecas da UFMS às normas de acessibilidade." (UFMS, 2016, p. 214). Tal indicativo instigou os autores a propor ações que visem adequar as bibliotecas da UFMS às políticas de acessibilidade vigentes no Brasil, refletindo sobre a influência que podem exercer na promoção da competência em informação. 


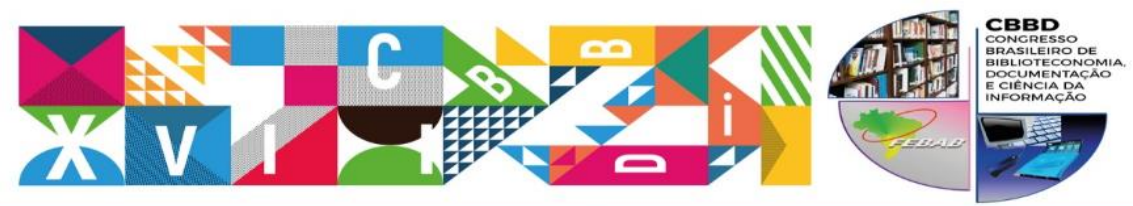

\section{CONGRESSO BRASILEIRO DE BIBLIOTECONOMIA, DOCUMENTAÇÃO E CIÊNCIA DA INFORMAÇÃO

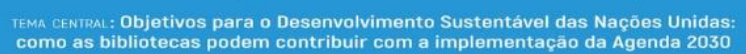

Atualmente, a UFMS possui em torno de 18.691 alunos regularmente matriculados, abrangendo a unidade de Campo Grande e mais 09 campi em cidades no interior do Estado de Mato Grosso do Sul. Deste total de alunos, 667 possuem alguma deficiência ${ }^{1}$, conforme descrito no quadro abaixo.

Quadro 1 - Alunos regularmente matriculados na UFMS

\begin{tabular}{|l|c|}
\hline \multicolumn{2}{|c|}{$\begin{array}{c}\text { ALUNOS REGULARMENTE MATRICULADOS NA UFMS } \\
\text { (CAMPO GRANDE + INTERIOR): 18.691 }\end{array}$} \\
\hline DEFICIÊNCIA & TOTAL DE ALUNOS \\
\hline Deficiente visual /baixa visão & 747 \\
\hline Deficientes auditivos & 31 \\
\hline Deficiente física & 5 \\
\hline Surdez & 5 \\
\hline Altas habilidades /superdotação & 3 \\
\hline Deficiente intelectual /mental & 1 \\
\hline Deficiência múltipla & 1 \\
\hline Deficiente visual /cegueira & $\mathbf{6 6 7}$ \\
\hline TOTAL DE ALUNOS COM DEFICIÊNCIA & \\
\hline EM CAMPO GRANDE SÃO 392 CASOS DE ALUNOS COM ALGUMA DEFICIÊNCIA \\
\hline
\end{tabular}

Fonte: UFMS, 2016, p. 211

Destacamos que só em Campo Grande são 392 casos de alunos que possuem alguma deficiência, sendo que mais de $80 \%$ se autodeclararam deficientes visuais. De acordo com Dorneles (2007, p.33):

\footnotetext{
${ }^{1}$ Estes dados devem ser considerados com ressalvas, pois muitos alunos que se autodeclararam no momento da matrícula, deficientes visuais e com baixa visão não foram confirmados com essa deficiência em entrevista realizada pela DIAAF. (UFMS, 2016, p. 21)
} 


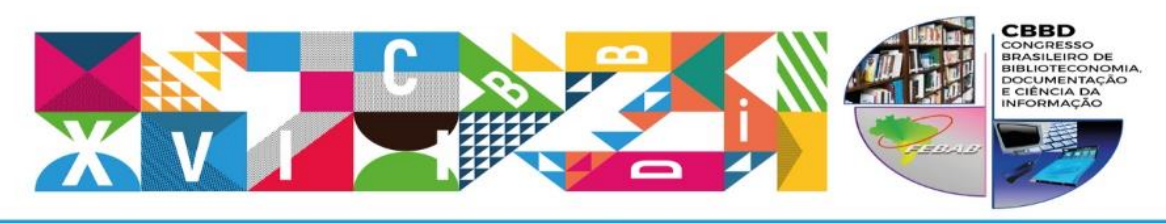

XXVII CONGRESSO BRASILEIRO DE BIBLIOTECONOMIA, DOCUMENTAÇÃO E CIÊNCIA DA INFORMAÇÃO

TEMA CENIPAl: Objetivos para o Desenvolvimento Sustentável das Naçōes Unidas:
como as bibliotecas podem contribuir com a implementaçáo da Agenda 2030

Consideram-se como baixa visão os indivíduos cuja capacidade visual foi diminuída por alteração significativa da acuidade visual, por redução relevante do campo de percepção e/ou diminuição da sensibilidade à luminosidade e aos contrastes. Conservam eles, porém, resíduos de visão.

Todos os alunos com alguma deficiência são usuários potenciais da biblioteca, justificando a importância de um estudo mais abrangente com essa comunidade para identificar suas necessidades de acessibilidade.

Em ambientes educacionais, principalmente em órgãos públicos como a Biblioteca Central da UFMS, a acessibilidade é uma questão sobre a qual deve-se ter extrema atenção. É preciso que seja um espaço que contribua para a redução da desigualdade, proporcionando ambientes de aprendizagem seguros e abertos, com infraestrutura, mobiliários, sistemas e equipamentos adequados para utilização por pessoas com deficiência (PcD) ou com mobilidade reduzida, com segurança e autonomia. Além disso, a lei prevê que a concepção de produtos, ambientes, programas e serviços devem atender aos princípios do desenho universal, que permite "serem usados por todas as pessoas, sem necessidade de adaptação ou de projeto específico, incluindo os recursos de tecnologia assistiva". (BRASIL, 2015, art. $8^{\circ}$, $\S 1^{\circ}$ ). Deste modo, o objetivo do trabalho é contribuir para o fortalecimento da política de inclusão da Biblioteca Central da UFMS.

A tecnologia assistiva ou ajuda técnica (BRASIL, 2015, art. 3o, III), abrange:

produtos, equipamentos, dispositivos, recursos, metodologias, estratégias, práticas e serviços que objetivem promover a funcionalidade, relacionada à atividade e à participação da pessoa com deficiência ou com mobilidade reduzida, visando à sua autonomia, independência, qualidade de vida e inclusão social.

Outra questão importante destacada na Lei no 13.146 , art. 68, que está relacionada ao acesso à informação e à comunicação, quando indica que

0 poder público deve adotar mecanismos de incentivo à produção, à edição, à difusão, à distribuição e à comercialização de livros em formatos acessíveis, inclusive em publicações da administração pública ou financiadas com 


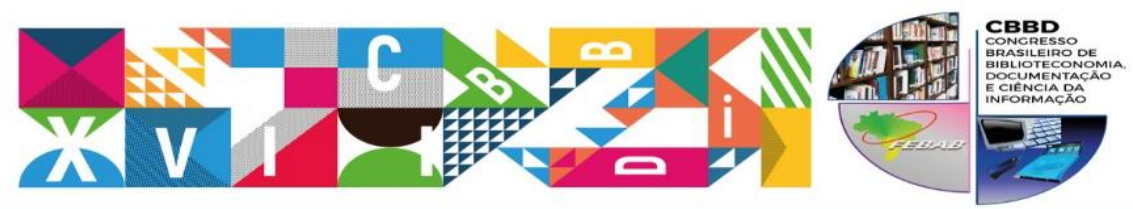

XXVII CONGRESSO BRASILEIRO DE BIBLIOTECONOMIA, DOCUMENTAÇÃ̃O E CIÊNCIA DA INFORMAÇÃO

TEMA ceNIPAL : Objetivos para o Desenvolvimento Sustentável das Naçōes Unidas:
como as bibliotecas podem contribuir com a implementaçao da Agenda 2030

recursos públicos, com vistas a garantir à pessoa com deficiência o direito de acesso à leitura, à informação e à comunicação. (BRASIL, 2015).

Desta forma, o presente artigo apresenta reflexões que evidenciam como a temática "acessibilidade" tem sido tratada por organismos internacionais como a ONU, e de que maneira as políticas existentes colaboram na promoção da competência em informação, especificamente na Biblioteca Central da UFMS.

\section{CONCEITUANDO ACESSIBILIDADE}

O Estatuto da Pessoa com Deficiência considera como PcD, “[...] aquela que tem impedimento de longo prazo de natureza física, mental, intelectual ou sensorial, o qual, em interação com uma ou mais barreiras, pode obstruir sua participação plena e efetiva na sociedade em igualdade de condições com as demais pessoas.” (BRASIL, 2015, art. 2º, p. 2).

Vivarta (2003, p.38) adverte sobre o cuidado que se deve ter com os termos 'portador' e 'deficiente':

pessoas com deficiência vêm argumentando que elas não portam uma deficiência como portamos um sapato ou uma bolsa. Já a palavra "deficiente" tem a desvantagem de tomar a parte pelo todo, sugerindo que a pessoa inteira é deficiente. É preferível a expressão "pessoa com deficiência", que reconhece a condição de determinado indivíduo, sem desqualificá-lo. Mas, atenção: a pessoa com deficiência é designada como "pessoa portadora de deficiência" na Constituição Brasileira, portanto, em um contexto jurídico, não escapamos da expressão consagrada nas leis.

Já a acessibilidade (BRASIL, 2015, art. 3oㅗㄱ), é definida como:

possibilidade e condição de alcance para utilização, com segurança e autonomia, de espaços, mobiliários, equipamentos urbanos, edificações, transportes, informação e comunicação, inclusive seus sistemas e tecnologias, bem como de outros serviços e instalações abertos ao público, de uso público ou privados de uso coletivo, tanto na zona urbana como na rural, por pessoa com deficiência ou com mobilidade reduzida. 


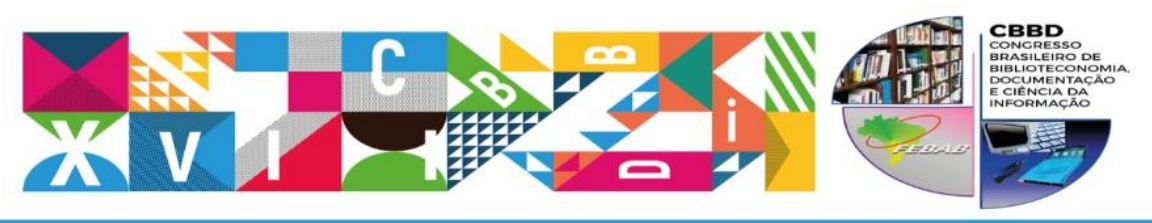

XXVII CONGRESSO BRASILEIRO DE BIBLIOTECONOMIA, DOCUMENTAÇÃO E CIÊNCIA DA INFORMAÇÃO

TEMA CeNIIRA: Objetivos para o Desenvolvimento Sustentável das Naçōes Unidas:
como as bibliotecas podem contribuir com a implementaçao da Agenda 2030

De acordo com Bulos (2007, p.1363) “A educação é o caminho para o homem evoluir. Por isso, é um direito público subjetivo, e, em contrapartida, um dever do Estado e do grupo familiar." E, somente dará oportunidades para o total desenvolvimento humano se identificar e considerar a diversidade humana. 0 fato de incluir alunos com deficiência na educação superior torna-se um desafio. Chauí (2003) lembra que a universidade tem a obrigação de realizar um papel democrático junto à sociedade e sempre posicionar-se contra a exclusão social e a privatização dos conhecimentos. Nesta percepção, as bibliotecas universitárias, devem estar alinhadas a esta realidade, oferecendo serviços e produtos diferenciados às pessoas que apresentam algum tipo de limitação (PUPO; MELO; FERRES; 2008).

Seguindo orientações da Agenda 2030 da Organização das Nações Unidas (ONU), para o desenvolvimento sustentável, é necessária uma educação inclusiva e de qualidade, destacando a aprendizagem ao longo da vida como mecanismo para sistemas equitativos de educação.

O documento da ONU (2015) ainda prevê no item 4.5 que as disparidades de gênero na educação deverão ser para todos os níveis de educação e formação profissional, incluindo os mais vulneráveis, como pessoas com deficiência, povos indígenas e crianças em situação de vulnerabilidade. Ainda neste sentido, o tópico 4a declara que é necessária a construção e melhorias das instalações físicas que sejam, dentre outros aspectos, apropriadas e sensíveis às deficiências e ao gênero, proporcionando ambientes de aprendizagem seguros e inclusivos para todos.

Por outro lado, e parte da mesma cadeia e pensamento global de desenvolvimento da humanidade e do indivíduo enquanto cidadão livre, crítico e capaz de se posicionar perante o ambiente em que vive, lembra-se que a competência em informação é ferramenta imprescindível de enfrentamento contra a vulnerabilidade social, sendo considerada um direito humano básico, promovendo a inclusão social em todas as nações (IFLA, 2005).

As limitações de quaisquer naturezas, das consideradas neste artigo, em geral influenciam a maneira como os sujeitos têm acesso à informação. A estes não se pode negar, 


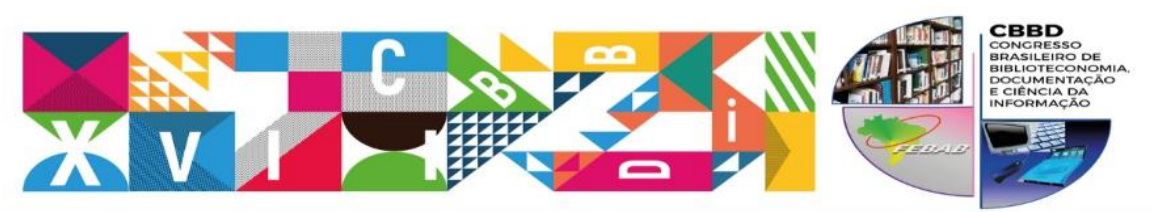

XXVII CONGRESSO BRASILEIRO DE BIBLIOTECONOMIA, DOCUMENTAÇÃOO E CIÊNCIA DA INFORMAÇÃO

TEMA cenvisal: Objetivos para o Desenvolvimento Sustentável das Naçöes Unidas:
como as bibliotecas podem contribuir com a implementaçao da Agenda 2030

dificultar ou negligenciar que tenham as suas necessidades informacionais sanadas. Ao contrário, a sociedade como um todo, e em especial as universidades e mais especificamente as bibliotecas devem ter um plano de ação para que estejam equipadas e preparadas, tanto fisicamente quanto às questões que envolvam o atendimento especializado deste usuário, para que se exerça o direito de cidadania, evitando um sistema de reprodução de desigualdades e desvantagens sociais.

No Brasil citamos como modelos de referência o Laboratório de Acessibilidade da UNICAMP, criado em 2002, com uma sala de acesso à informação, coordenada por uma bibliotecária e o Laboratório de Apoio Didático e Tecnológico, coordenados por uma pedagoga, ambos localizados no espaço da biblioteca (UNICAMP, 2016). Também na Biblioteca Central da UFSC, o Ambiente de Acessibilidade Informacional criado em 2010, tem o objetivo de atender de forma exclusiva os estudantes da instituição que apresentam alguma deficiência. (UFSC, 2016)

Em ambos os exemplos, os serviços oferecidos são: leituras e digitalização de material didático, disponibilização de tecnologia assistiva, áudio-books e livros em braile, realização de impressões e computadores com softwares específicos.

\section{UMA AGENDA PELA ACESSIBILIDADE: POR UMA EDUCAÇÃO INCLUSIVA E EQUITATIVA}

Embora tenha sido adotada em setembro de 2015 pelos 193 Estados-membros da ONU, a Agenda 2030 começou a ser definida em 2012, durante a Rio+20, por meio de processo participativo que teve como finalidade uma agenda global de desenvolvimento. Segundo a ONU (2015, p. 1) “[...] é um plano de ação para as pessoas, para o planeta e para a prosperidade."

A Agenda 2030 compõem-se de uma Declaração (incluindo visão, princípios e compromissos compartilhados), 17 Objetivos de Desenvolvimento Sustentável (ODS) e suas 169 metas, uma seção sobre meios de implementação e de parcerias globais, e um roteiro 


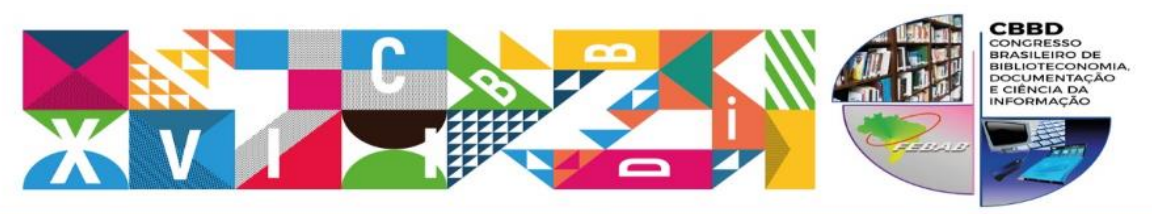

XXVII CONGRESSO BRASILEIRO DE BIBLIOTECONOMIA, DOCUMENTAÇÃ̃O E CIÊNCIA DA INFORMAÇÃO

TEMA CENIPAs: Objetivos para o Desenvolvimento Sustentável das Naçōes Unidas:
como as bibliotecas podem contribuir com a implementaçăo da Agenda 2030

para acompanhamento e revisão. No documento também está estabelecido que os ODS e suas metas serão acompanhados por meio de indicadores. (ONU, 2015).

A educação faz parte da visão da agenda, pois pretende "um mundo com alfabetização universal. Um mundo com o acesso equitativo e universal à educação de qualidade em todos os níveis [...]" (ONU, 2015, p. 4). Ou seja, a proposta da ONU é abranger níveis da primeira infância, primário, ensinos secundário, superior, técnico e profissional e para todos, não sendo redundante falar que isso independe do sexo, raça, etnia, se migrantes, indígenas, com deficiência, crianças, jovens ou adultos. Destaque para os grupos vulneráveis, que de acordo com a ONU (2015), a estes também deve ser oportunizada a aprendizagem ao longo da vida, que os ajudará a participar plenamente da sociedade, tendo em vista que conhecimentos e habilidades necessários serão adquiridos e lhes ajudarão a explorar as oportunidades para a realização de direitos e exercício da cidadania.

De acordo com Séguin (2002), a luta pelos direitos das minorias e dos grupos vulneráveis pode ser feita com a não omissão e ações afirmativas, e sobretudo:

[...] permitindo o acesso à educação e aos Tribunais. Professamos também a certeza de que a educação deve ser utilizada como meio de transformar realmente os homens em irmãos, pois mesmos os irmãos são diferentes como os dedos de nossa mão. Não pactuar com a intolerância e dar a todos o acesso à educação são as melhores formas de resistir... (SÉGUIN, 2002, p. 34).

Já na visão de Abramovay et al. (2002, p. 29) , entende-se a vulnerabilidade social “[...] como o resultado negativo da relação entre a disponibilidade dos recursos materiais [...] dos atores [...] e o acesso à estrutura de oportunidades sociais, econômicas, culturais..." Sendo assim, a vulnerabilidade social oferece, aos que nesta situação encontram-se, menos oportunidades à ascensão dos níveis de bem-estar, deterioração das condições de vida, criando assim, sentimento de instabilidade, impotência e insegurança. Para Aragão (2011), não existe uma vulnerabilidade social, mas sim várias vulnerabilidades sociais, sendo estas geralmente cumulativas. Dentre as consideradas pelo autor, estão as vulnerabilidades etárias, vulnerabilidades econômicas, vulnerabilidades culturais e vulnerabilidades 


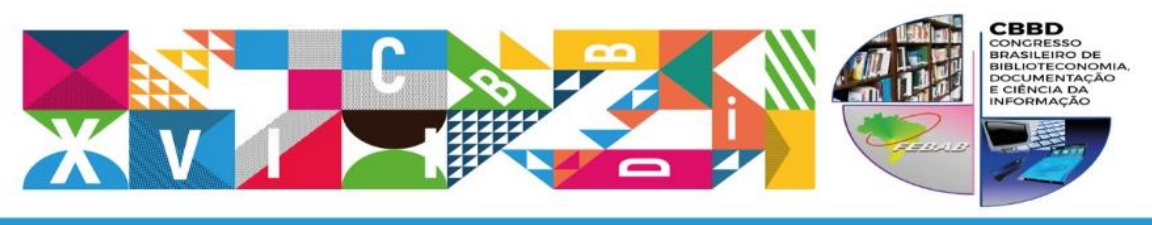

XXVII CONGRESSO BRASILEIRO DE BIBLIOTECONOMIA, DOCUMENTAÇÃ̃o E CIÊNCIA DA INFORMAÇÃO

TEMA CENIPAl: Objetivos para o Desenvolvimento Sustentável das Naçōes Unidas:
como as bibliotecas podem contribuir com a implementaçáo da Agenda 2030

resultantes de exclusão social. Consideramos para fins deste trabalho, a vulnerabilidades pessoais que dizem respeito às dificuldades enfrentadas por pessoas doentes e/ou deficientes.

O objetivo 4 da Agenda "Assegurar a educação inclusiva e equitativa e de qualidade, e promover oportunidades de aprendizagem ao longo da vida para todos" mostra a preocupação da ONU e consequentemente dos países que participaram de sua elaboração, de que a educação deve ser uma prioridade e um mecanismo de luta para que os demais objetivos também consigam ser alcançados. Ou seja, questões que envolvam disparidades ou igualdade de gênero, sustentabilidade, empreendedorismo, dentre outras. Se a educação é de fato para muitos a única forma e esperança de acesso à sociedade, ela precisa ser pensada para toda a vida. Assim, no item 4.4 o documento ressalta que deverá aumentar até 2030 “[...] o número de jovens e adultos que tenham habilidades relevantes, inclusive competências técnicas e profissionais, para emprego, trabalho decente e empreendedorismo." (ONU, 2015, p 23).

Ainda no objetivo 4, a acessibilidade está expressamente presente no item 4.5 quando menciona a meta de garantir a igualdade de acesso para os mais vulneráveis, dentre elas, as pessoas com deficiência. Também, identifica-se tal preocupação quando o documento menciona a meta de construção e melhoria de instalações físicas para educação, dentre outros aspectos, sensíveis às deficiências “[...] e que proporcionem ambientes de aprendizagem seguros e não violentos, inclusivos e eficazes para todos." (ONU, 2015, p. 23).

A International Federation of Library Associations and Institutions (IFLA) publicou um documento com orientações sobre como as bibliotecas podem contribuir com a Agenda 2030. Isto leva-nos a reflexão de que as bibliotecas tenham elas as denominações (e missões) que tiverem, não podem passar por este processo de discussões, passivamente: sejam elas públicas, particulares, escolares ou universitárias, como é o caso da Biblioteca Central da UFMS. Menciona o documento: “Las bibliotecas junto a otros organismos y la sociedad civil tienen un papel importante en monitorear el proceso y cerciorarse de que los gobiernos estén completamente a la altura de los ODS." (IFLA, 2015, p. 12). Precisam as instituições de ensino 


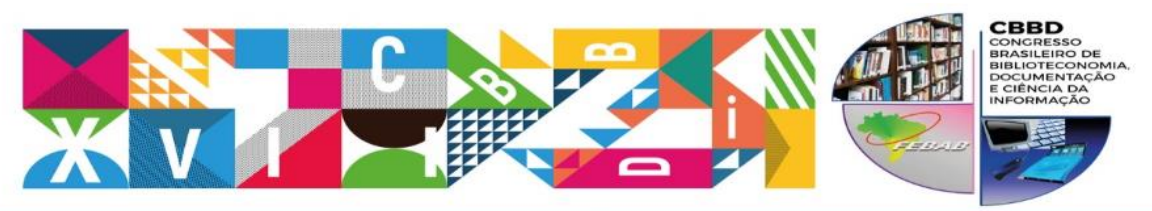

XXVII CONGRESSO BRASILEIRO DE BIBLIOTECONOMIA, DOCUMENTAÇÃ̃O E CIÊNCIA DA INFORMAÇÃO

TEMA CENIPAs: Objetivos para o Desenvolvimento Sustentável das Naçōes Unidas:
como as bibliotecas podem contribuir com a implementaçao da Agenda 2030

superior, em especial as bibliotecas universitárias, fazer também a sua parte no que concerne a sua contribuição ao desenvolvimento da agenda, pois de acordo com a IFLA ([2015?], não paginado) "as bibliotecas são instituições fundamentais para se alcançar esses objetivos.”

Uma ação básica seria informar aos seus usuários sobre os ODS e mostrar à sociedade que fazemos parte destas reflexões e luta por uma educação inclusiva e equitativa, para todos. A IFLA (2015, p. 13, grifo nosso) recomenda:

Se ha pedido a cada país asegurarse de que todas las personas conozcan los ODS y cómo estos se aplican a nivel nacional y local. Los bibliotecólogos pueden apoyar en esta tarea. Cada bibliotecario tiene un papel en la Agenda 2030 de la ONU en el cual se cerciore que toda persona que visite las bibliotecas conozca las metas.

Uma ação concreta em nível local reflete as discussões apresentadas neste artigo que é a preocupação em proporcionar ambientes acessíveis de forma segura e sem barreiras para que os usuários da Biblioteca Central da UFMS e pessoas da comunidade em geral, possam ter acesso às informações de que necessitem. Segundo a IFLA (2015), as bibliotecas e o acesso à informação que promovem, apoiam todos os ODS, e no âmbito de uma biblioteca universitária, o fazem atuando como centro da comunidade acadêmica e de pesquisa, tendo em vista que:

As bibliotecas são o coração das escolas, universidades e institutos em todos os países do mundo. As bibliotecas apoiam programas de alfabetização, oferecem um lugar seguro para a aprendizagem e colaboram com pesquisadores na utilização de dados e informações para gerar novos conhecimentos. (IFLA, [2015?], não paginado).

Dessa forma, a Biblioteca Central da UFMS, enquanto um espaço de produção e disseminação de conhecimento precisa apresentar iniciativas nas proposições de ações que visem à promoção de condições acessíveis para garantir o ingresso e permanência de alunos, incluindo aqueles que possuem algum tipo de deficiência. 0 desafio de tornar um ambiente 


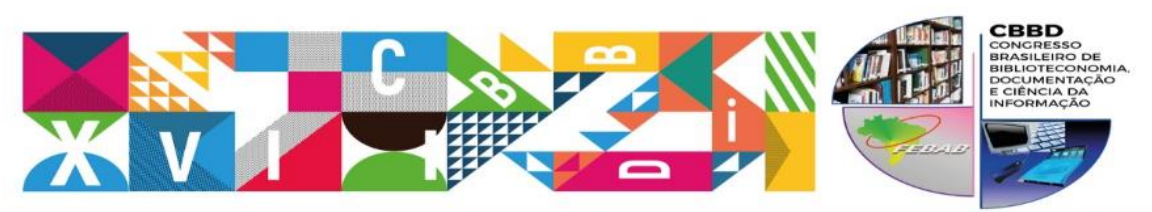

XXVII CONGRESSO BRASILEIRO DE BIBLIOTECONOMIA, DOCUMENTAÇÃO E CIÊNCIA DA INFORMAÇÃO

TEMA cENIPAL : Objetivos para o Desenvolvimento Sustentável das Naçöes Unidas:
como as bibliotecas podem contribuir com a implementaçao da Agenda 2030

acessível vai além de considerar apenas estruturas prediais e urbanísticas. Essa compreensão é o princípio necessário para que as bibliotecas contribuam para uma educação inclusiva e equitativa para todos.

\section{INFLUÊNCIA DAS POLÍTICAS DE ACESSIBILIDADE NA PROMOÇÃO DA COMPETÊNCIA EM INFORMAÇÃO}

Não se trata apenas da participação, mas da inclusão na sociedade. 0 que se reivindica não é apenas a acessibilidade, mas a luta é pela igualdade de oportunidades, assim como pela não discriminação das pessoas com deficiências, que apresentam particularidades e precisam ser consideradas quando as políticas públicas são discutidas. Aliás, essas pessoas precisam ser parte e precisam ter voz na elaboração e na construção dessas políticas.

De acordo com documento elaborado por ocasião da III Conferência Nacional dos Direitos da Pessoa com Deficiência, realizado em Brasília no ano de 2012, nos últimos anos o Brasil avançou no quesito promoção dos direitos das pessoas com deficiência, e isso tem sido feito por meio de políticas públicas que valorizam a pessoa como cidadã, pois levam em consideração e respeitam as suas características e especificidades. 0 documento considera que “a ordenação de ações políticas e econômicas deve garantir a universalização de políticas sociais e o respeito às diversidades, sejam elas étnico-raciais, geracionais, de gênero, de deficiência ou de qualquer outra natureza." (BRASIL, 2012, p. 15).

Em uma biblioteca universitária, políticas que promovam a acessibilidade concorrem para a promoção da competência em informação, na medida em que esta é considerada um direito fundamental da pessoa humana ou que concorre para os direitos humanos, e com a capacidade de promover o acesso de pessoas em condições de vulnerabilidade a um estado de cidadania, identidade e autonomia perante a sociedade em que vive. Documentos como o Manifesto de Florianópolis (2013), Declaração de Alexandria (2005), Declaração de Lyon (2014) confirmam essa assertiva. 


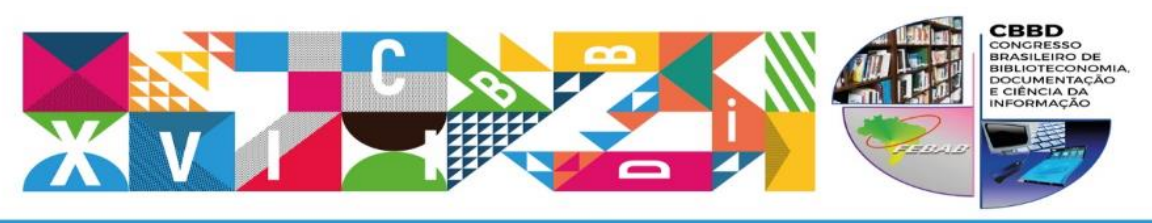

XXVII CONGRESSO BRASILEIRO DE BIBLIOTECONOMIA, DOCUMENTAÇÃ̃O E CIÊNCIA DA INFORMAÇÃO

TEMA CENIPAl: Objetivos para o Desenvolvimento Sustentável das Naçōes Unidas:
como as bibliotecas podem contribuir com a implementaçao da Agenda 2030

O Manifesto de Florianópolis sobre a competência em informação e as populações vulneráveis e minorias (2013) corrobora tal assertiva quando considera que o Brasil precisa reavaliar as suas políticas voltadas a tais grupos. Considera que os mesmos encontram-se em situações de discriminação, intolerância e fragilidade e que o acesso e uso da informação lhes permitirá a sua inclusão social, já que através do acesso terão condições da construção do conhecimento, formação de identidade e garantia da autonomia.

O Manifesto de Florianópolis prevê ainda uma série de recomendações e ações, conclamando os profissionais bibliotecários a assumirem uma postura pró-ativa no sentido de enfrentar as dificuldades apresentadas por tais grupos através de um programa voltado à competência em informação, entendendo que assim, terão maiores chances de escapar da exclusão social. Desta forma, sugere por exemplo, "elaborar produtos e serviços especiais/customizados para atender demandas de informação." (MANIFESTO, 2013, p. 3). 0 referido documento sugere ainda que se capacite docentes e servidores públicos para que tenham a sua própria competência em informação desenvolvida, para que desta forma, estejam aptos ao atendimento às necessidades informacionais das populações vulneráveis e minorias.

A competência em informação também é um agente facilitador para a promoção da educação e aprendizagem ao longo da vida dos grupos sociais menos favorecidos, dentre eles as pessoas com deficiência. Segundo Dudziak (2008) a competência em informação supera atividades de busca, organização ou uso de informações, mas está relacionada à cidadania, tendo em vista que diz respeito ao porquê desse uso e envolve concepções ideológicas, políticas e/ou ambientais.

Levando-se em conta que a Declaração de Alexandria (2005) compreende a competência em informação no cerne do aprendizado ao longo da vida, a Agenda 2030, em especial por meio do seu ODS 4, pode ser a força política que levará à consolidação definitiva da competência em informação, principalmente nas bibliotecas universitárias.

Outrossim, a Declaração de Lyon sobre o Acesso à Informação e Desenvolvimento (2014), estabelece um compromisso internacional para uso da agenda de desenvolvimento 


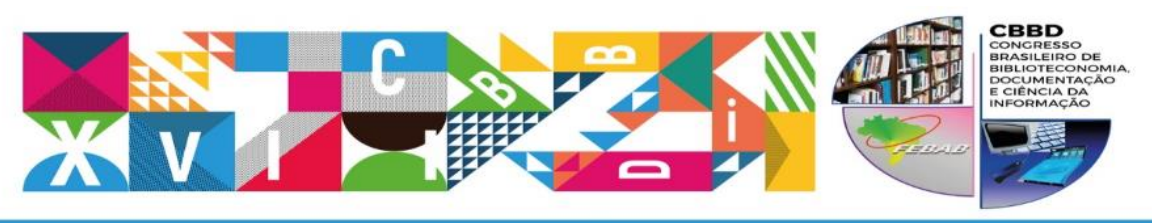

XXVII CONGRESSO BRASILEIRO DE BIBLIOTECONOMIA, DOCUMENTAÇÃ̃O E CIÊNCIA DA INFORMAÇÃO

TFMa ceniral: Objetivos para o Desenvolvimento Sustentável das Naçöes Unidas:
como as bibliotecas podem contribuir com a implementaçao da Agenda 2030

pós-2015, constando em seus princípios que o direito à informação é transformacional. A declaração reconhece que a erradicação da pobreza está vinculada ao desenvolvimento sustentável, devendo este ocorrer em uma estrutura pautada em direitos humanos em que a "desigualdade seja reduzida mediante a capacitação, educação e inclusão de grupos marginalizados, incluindo mulheres, povos indígenas, minorias, imigrantes, refugiados, pessoas com deficiência, idosos, crianças e jovens." (IFLA, 2014, p.1, tradução nossa).

Importante destacar que a Declaração de Lyon (2014) menciona que bibliotecas e arquivos (dentre outros intermediários da informação) podem ajudar e colaborar com os governos, instituições e indivíduos no sentido de comunicar, organizar, estruturar ou compreender os dados que são fundamentais para o desenvolvimento. Dentre as ações sugeridas, ressalta-se a que menciona a preservação e garantia do acesso permanente ao patrimônio cultural e informações, por exemplo. Entende-se que uma biblioteca universitária preocupada em melhorar suas políticas de inclusão de acessibilidade está facilitando o acesso à informação. Outra ação, como o oferecimento de treinamentos, desenvolvendo habilidades para ajudar as pessoas a acessar e compreender as informações e os serviços que lhes são mais úteis também exemplifica que as unidades de informação são reconhecidas (e elas também precisam reconhecer-se como tal) por organismos de alcance mundial como parceiras no enfrentamento da pobreza e aliadas para o desenvolvimento sustentável do planeta, bem como promotoras da competência em informação.

\section{MÉTODO DA PESQUISA}

O presente trabalho caracteriza-se por um estudo de caso com enfoque qualitativo, que de acordo com Nascimento e Sousa (2017, p. 74):

É baseado na interpretação dos fenômenos observados e no significado que carregam, ou no significado atribuído pelo pesquisador, dada a realidade em que os fenômenos estão inseridos. Considera a realidade e a particularidade de cada sujeito objeto da pesquisa. 


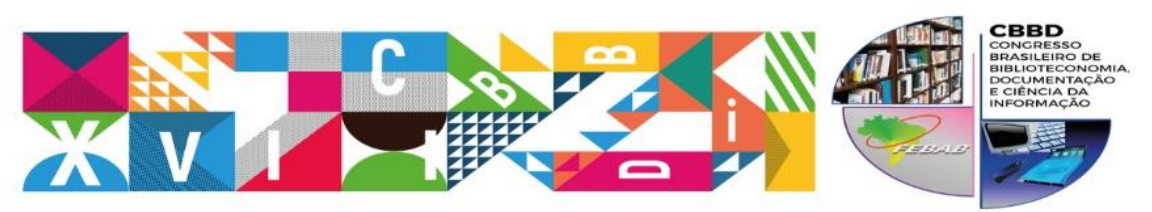

\section{CONGRESSO BRASILEIRO DE BIBLIOTECONOMIA, DOCUMENTAÇÃ̃O E CIÊNCIA DA INFORMAÇÃO \\ TEMA cENIRAL: Objetivos para o Desenvolvimento Sustentável das Naçóes Unidas:
como as bibliotecas podem contribuir com a implementação da Agenda 2030}

Foi realizado um levantamento dos aportes legais sobre o assunto, consultando leis, portarias, resoluções, decretos e relatórios, bem como sites das bibliotecas da Universidade Estadual de Campinas e da Universidade Federal de Santa Catarina, que se tornaram modelos de bibliotecas com políticas de acessibilidade, a fim de verificar as políticas existentes na questão da acessibilidade no ambiente da Biblioteca Central da UFMS.

Junto a isto, também foi utilizada a observação direta pelos autores a partir das exigências da NBR 9050/201 - atualmente na terceira versão - que trata de critérios de acessibilidade para edificações, mobiliários, espaços e equipamentos urbanos. Apresentamos ainda, alguns resultados e conclusões das práticas e políticas de acessibilidade para a Biblioteca Central da UFMS.

\section{RESULTADOS E DISCUSSÕES}

A NBR 9050 estabelece critérios a serem observados para que se tenham condições de acessibilidade. A partir de uma análise de alguns itens constantes na referida norma, percebe-se que alguns espaços na biblioteca da UFMS foram projetados a fim de atender as pessoas com deficiência e outros precisam de adaptação:

Quadro 2 - Acessibilidade na Biblioteca Central conforme NBR 9050/2015

\begin{tabular}{|l|c|c|}
\hline \multicolumn{1}{|c|}{ NBR 9050 } & Sim & Não \\
\hline Acesso a internet (10.16.6) & $\mathrm{x}$ & $\mathrm{x}$ \\
\hline Balcão (9.2) & $\mathrm{x}$ & \\
\hline Bebedouro (8.5) & $\begin{array}{c}\text { Parcial (falta distância } \\
\text { para manobra) }\end{array}$ & \\
\hline Corredores entre estantes (10.16.3) & $\mathrm{x}$ & \\
\hline Elevador (6.10.2) & $\mathrm{x}$ & \\
\hline Mesas acessíveis (10.16.2) & & $\mathrm{x}$ \\
\hline Piso tátil externo (5.4.6.4) & Parcial & \\
\hline Porta nos padrões (6.11.2) & $\mathrm{x}$ & \\
\hline Publicações em Braille (10.16.5) & & \\
\hline Terminais de consulta e autoempréstimo (10.16.1) & & \\
\hline
\end{tabular}




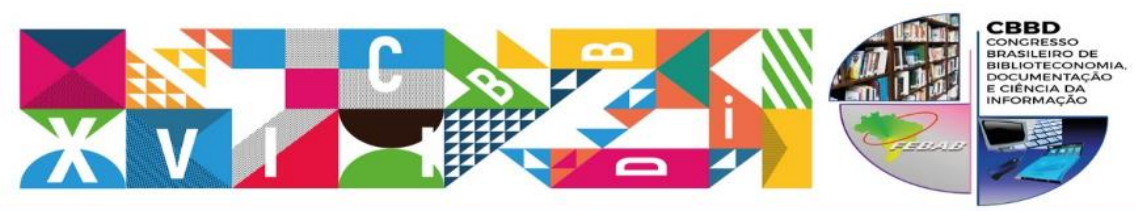

XXVII CONGRESSO BRASILEIRO DE BIBLIOTECONOMIA, DOCUMENTAÇÃOO E CIÊNCIA DA INFORMAÇÃO

TEMA CENIRA : Objetivos para o Desenvolvimento Sustentável das Naçōes Unidas:
Como as bibliotecas podem contribuir com a implementaçaa da Agenda 2030

Fonte: Elaboração própria (2017)

Observando os 10 requisitos consultados na NBR 9050/2015 referente a acessibilidade em biblioteca, 04 deles não atendem ao que está estabelecido na norma, sendo eles:

O balcão não está acessível para cadeirantes, é necessário que em pelo menos 0,90 m de sua extensão, a altura deva ser entre $0,73 \mathrm{~m}$ e $0,90 \mathrm{~m}$, permitindo a aproximação frontal dos cadeirantes. Detectamos que a altura do balcão é de 1,12 m, sendo vazado em sua parte frontal na altura de 0,60 para a passagem de livros, porém, com um tampo superior em mármore que não encontra-se na altura recomendada pelas normas vigentes.

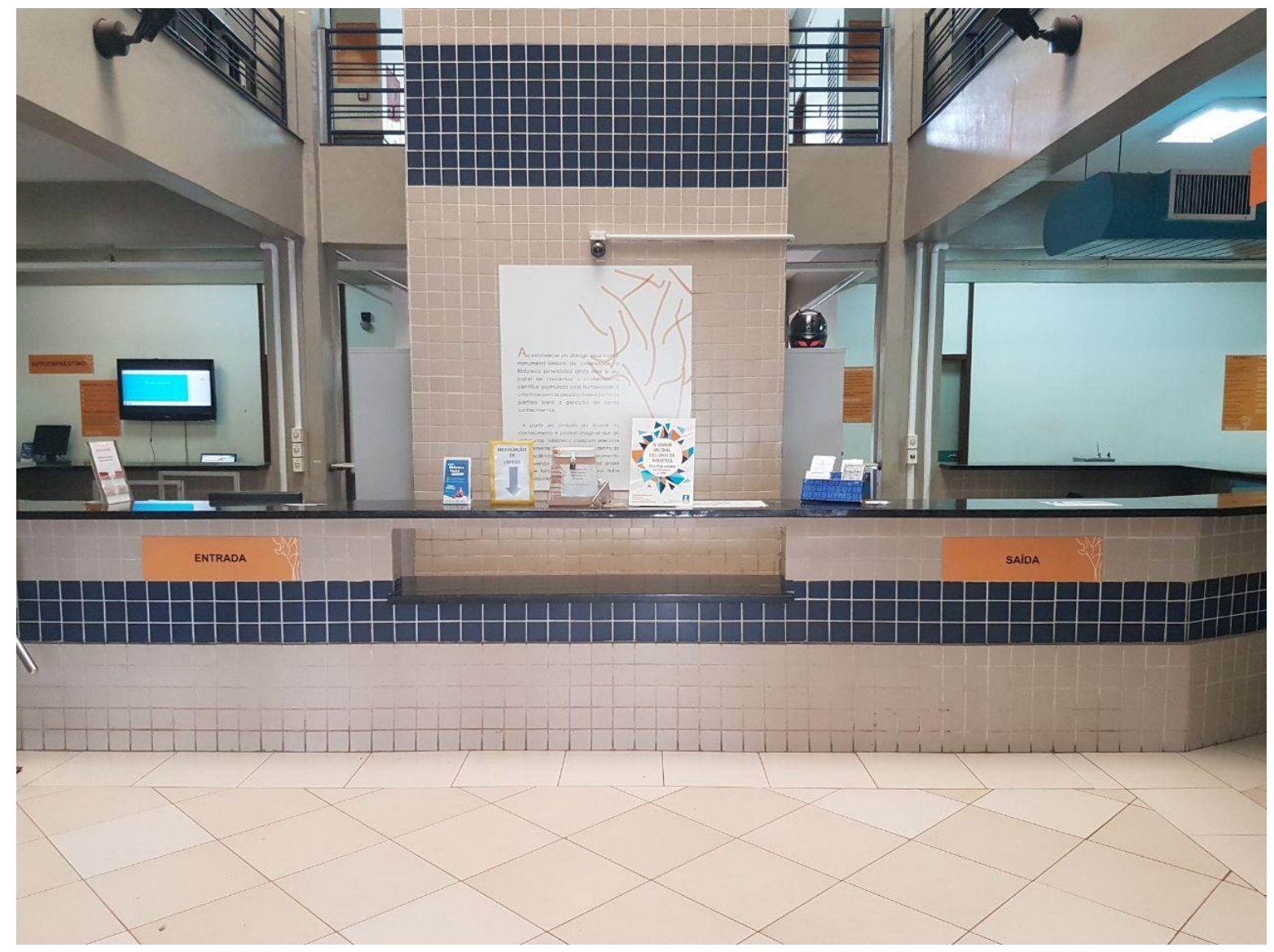




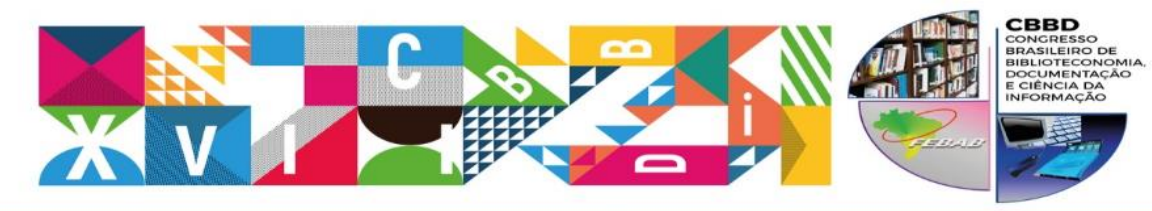

XXVII CONGRESSO BRASILEIRO DE BIBLIOTECONOMIA,
DOCUMENTAÇÃOO E CIÊNCIA DA INFORMAÇÃO
TEMA cENIRA : Objetivos para o Desenvolvimento Sustentável das Naçōes Unidas:
como as bibliotecas podem contribuir com a implementaçao da Agenda 2030

Os espaços entre prateleiras estão inadequados para a circulação e manobras de um cadeirante, sendo necessário providenciar espaçamento entre as estantes com a largura suficiente de no mínimo 0,90 m de largura e se atentar quando houver mudanças no layout para não comprometer a observância de largura.

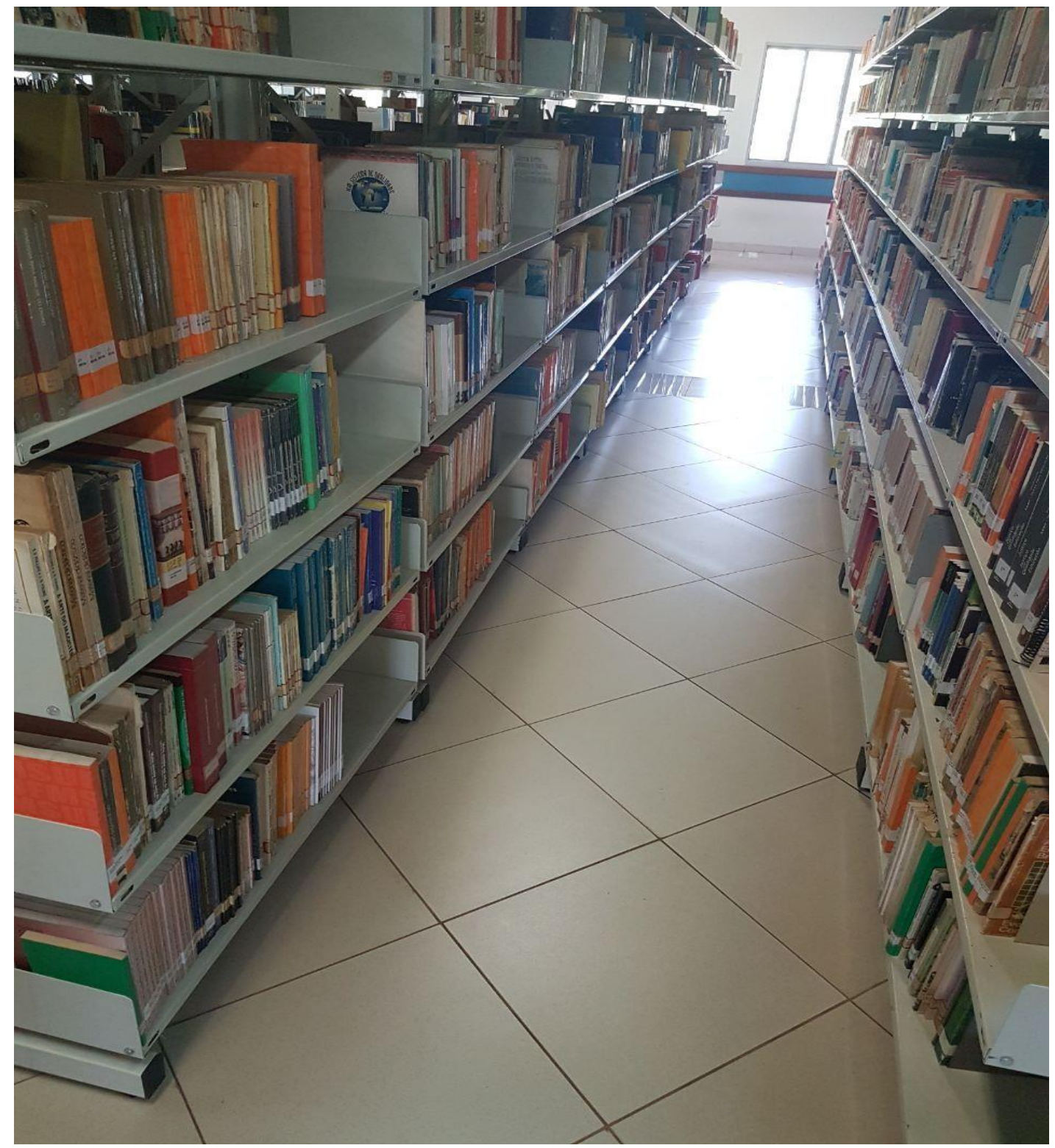

A porta de entrada é de vidro, com uma faixa ao longo de sua largura, não possui maçaneta, sendo aberta com um único movimento que fecha logo em seguida, e também não 


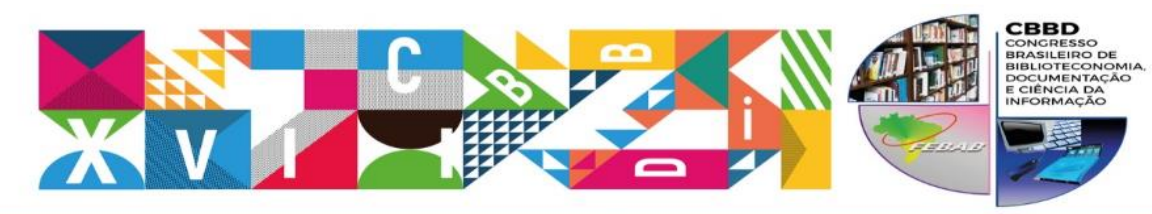

XXVII CONGRESSO BRASILEIRO DE BIBLIOTECONOMIA,
DOCUMENTAÇÃOO E CIÊNCIA DA INFORMAÇÃO
TEMA cENIRA : Objetivos para o Desenvolvimento Sustentável das Naçōes Unidas:
como as bibliotecas podem contribuir com a implementaçao da Agenda 2030

existe sinalização tátil até a porta principal. A porta que dá acesso ao estacionamento permanece trancada por questões de segurança ficando somente a entrada principal que possui detector de segurança.

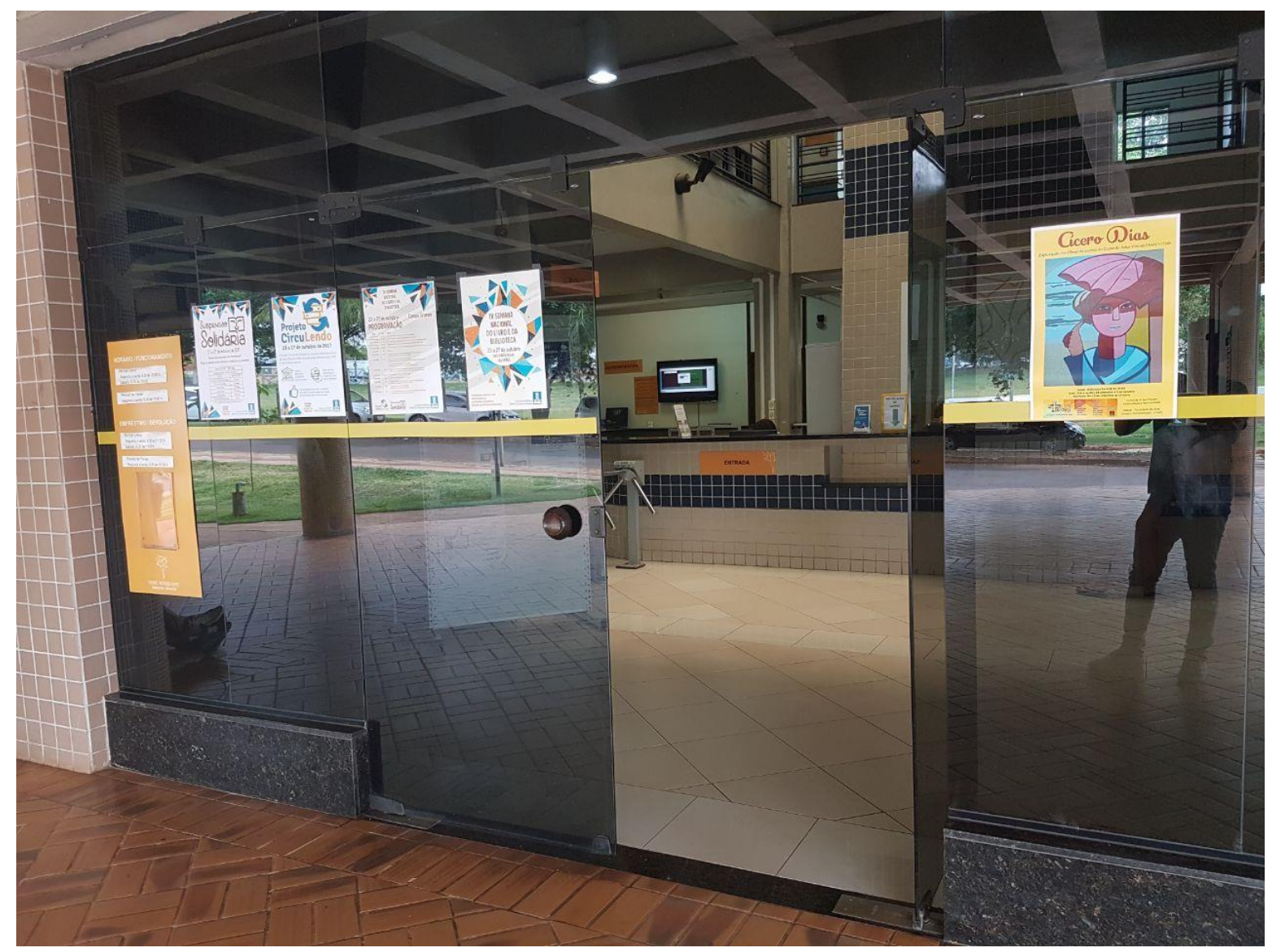

Em relação a publicações em braille, o leitor com deficiência visual deve dispor de publicações em que possam ter contato no suporte adequado. Na biblioteca há um espaço disponível para algumas revistas, porém o material é em número reduzido e esse espaço também é utilizado para pesquisas na internet com acadêmicos, não existindo um espaço específico para essa finalidade, também não existe no plano de desenvolvimento de coleções solicitações de obras ou recursos em formatos acessíveis aos deficientes visuais. 

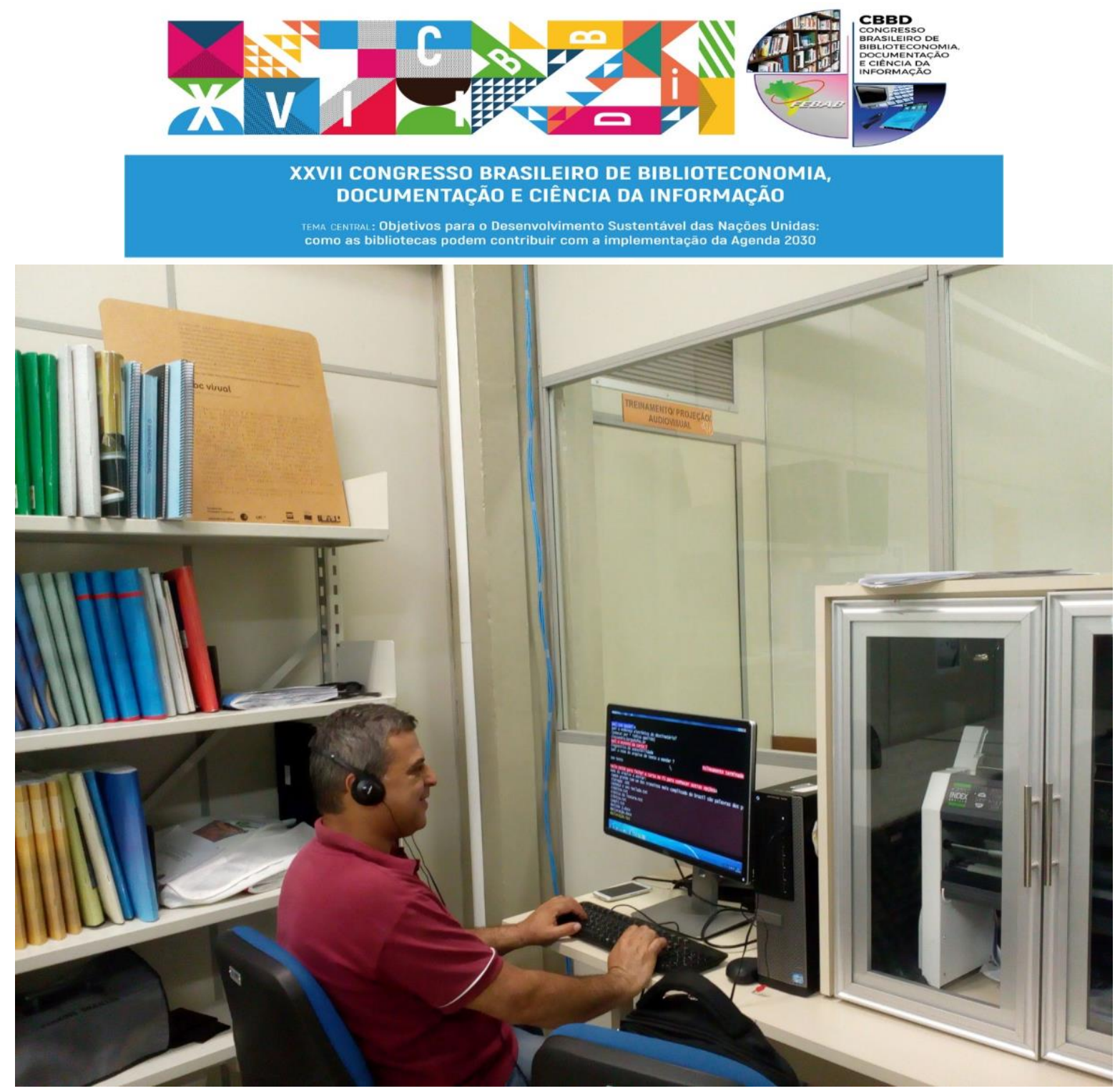

A Lei Brasileira de Inclusão (LIB) considera como formato acessível, os arquivos digitais que possam ser reconhecidos e acessados por softwares leitores de telas ou outras tecnologias assistivas que vierem a substituí-los, permitindo a leitura de voz sintetizada, ampliação de caracteres, diferentes contrastes e impressão em braille.

A mesma Lei estabelece no seu art. 42ํㅡ, I que "é vedada a recusa de obra intelectual em formato acessível sob qualquer argumento, inclusive sob a alegação de proteção dos direitos de propriedade intelectual".

A partir da vigência da LIB, todos os livros publicados pelas editoras em formato físico, também devem estar disponíveis em formato acessível. Desse modo, o Ministério Público Federal realizou um acordo em julho de 2017 com o Sindicato Nacional de Editores de Livros (SNEL) para garantir a disponibilização de livros em formatos acessíveis para pessoas com deficiência visual. 0 Termo de Ajustamento de Conduta (TAC) firmado entre a Procuradoria 


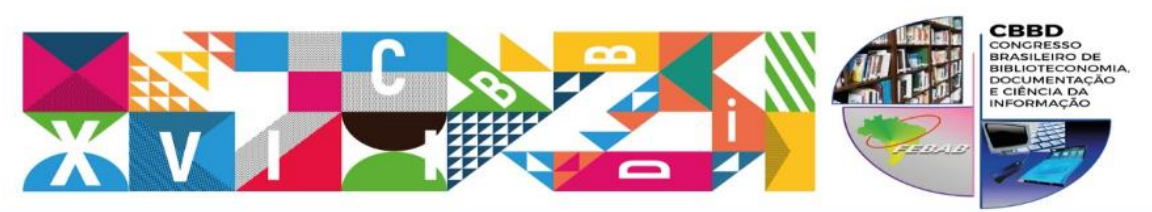

XXVII CONGRESSO BRASILEIRO DE BIBLIOTECONOMIA, DOCUMENTAÇÃ̃O E CIÊNCIA DA INFORMAÇÃO

TEMa CENIPAl: Objetivos para o Desenvolvimento Sustentável das Naçöes Unidas:
como as bibliotecas podem contribuir com a implementaçao da Agenda 2030

e as editoras prevê que o livro em formato acessível estará disponível para compra em uma plataforma online administrada pelo sindicato.

A negativa não justificada no fornecimento de livros em formato acessível pode constituir prática de discriminação de pessoa em razão de sua deficiência, crime com pena de reclusão de um a três anos e multa (BRASIL, 2015).

Desse modo, a acessibilidade é imprescindível para atender aos requisitos essenciais das pessoas com deficiência, de maneira que tenham acesso a todos os ambientes da biblioteca, de forma autônoma, com segurança e priorizando sua igualdade.

\section{CONSIDERAÇÕES FINAIS OU CONCLUSÕES}

Os resultados apontam que a UFMS possui a Divisão de Acessibilidade e Ações Afirmativas (DIAAF), unidade responsável pelo desenvolvimento de ações que promovem a acessibilidade e a política afirmativa, porém há a necessidade de desenvolver parcerias com a biblioteca para permitir que as necessidades educacionais especiais sejam garantidas, sendo possível que a PcD possa realizar seus estudos e pesquisas com maior autonomia e independência.

Sendo assim, a biblioteca precisa estar preparada em todos os aspectos para promover a tecnologia assistiva dentro dos padrões do desenho universal, principalmente em relação aos produtos e serviços oferecidos aos seus usuários, de forma que contemple a todos, sem distinção ou diferenciação que impeça ou limite a participação social de qualquer pessoa, eliminando todo tipo de barreira, seja atitudinal, comportamental, tecnológica ou nas comunicações e na informação (BRASIL, 2015).

Propomos então, a criação de um grupo de acessibilidade para articular as ações de implantação na biblioteca, podendo este ser coordenado por um servidor da DIAAF, que também fará a capacitação dos servidores, atendendo ao Decreto 3298/99, que prevê além da integração da PcD, a formação de recursos humanos para atendê-la. 


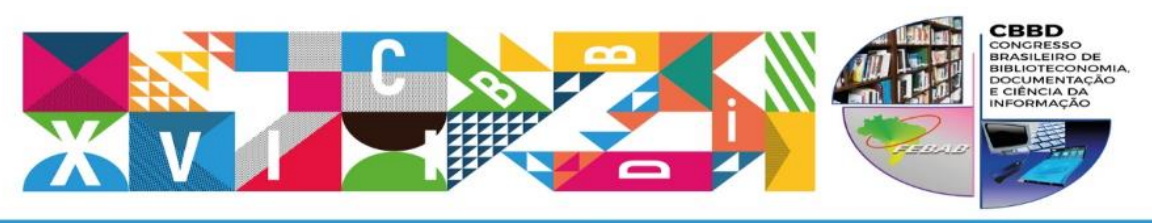

XXVII CONGRESSO BRASILEIRO DE BIBLIOTECONOMIA, DOCUMENTAÇÃ̃O E CIÊNCIA DA INFORMAÇÃO

TEMA cENIral : Objetivos para o Desenvolvimento Sustentável das Naçōes Unidas:
como as bibliotecas podem contribuir com a implementaçao da Agenda 2030

Além disso, os servidores precisam ser capacitados para promover as atividades e serviços da biblioteca com a funcionalidade necessária, de maneira que permita autonomia, independência, qualidade de vida e inclusão social às pessoas com deficiência, desenvolvendo nelas a competência em informação, que é considerada uma ferramenta que proporciona a aprendizagem ao longo da vida.

Portanto, justificam-se investimentos em treinamento, adequações na infraestrutura, mobiliários e equipamentos acessíveis visando a eliminação de barreiras, sobretudo a atitudinal, em consonância com o Estatuto da Pessoa com Deficiência, que se destina a assegurar e a promover, em condições de igualdade, o exercício dos direitos e das liberdades fundamentais por pessoa com deficiência, visando a sua inclusão social.

Também apontamos a necessidade das bibliotecas da rede da UFMS em atualizar seus acervos com livros e outros materiais bibliográficos em formatos acessíveis, oferecendo com isso, maiores condições para que esses usuários utilizem dados e informações para gerar novos conhecimentos.

Entendemos que as ações propostas contribuem para a promoção da competência em informação, como parte de ações educativas de uma biblioteca, constituindo-se em instrumento de resistência pacífica contra toda ordem de mazelas que possam colocar em xeque a existência de equilíbrio de um indivíduo e o seu convívio em paz perante a sociedade. As bibliotecas universitárias devem possuir a competência de buscar, através de tecnologias de informação, diversas possibilidades para partilhar e colaborar na metodologia de aprendizagem, proporcionando assim, o acesso ao conhecimento e possibilitando a garantia do direito à educação.

\section{REFERÊNCIAS}

ABRAMOVAY, M. et al. Juventude, violência e vulnerabilidade social na América Latina: desafios para políticas públicas. Brasília: UNESCO, BID, 2002. p.1-89.

ARAGÃO. A. Prevenção de riscos na União Europeia: o dever de tomar em consideração a vulnerabilidade social para uma proteç̧ão civil eficaz e justa. Revista Crítica de Ciências Sociais. 


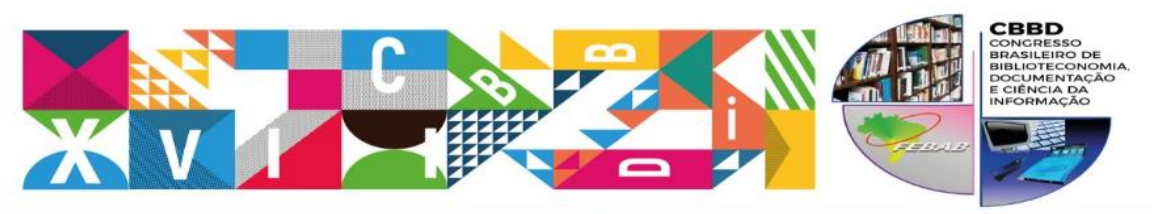

XXVII CONGRESSO BRASILEIRO DE BIBLIOTECONOMIA, DOCUMENTAÇÃO E CIÊNCIA DA INFORMAÇÃO

TEMA CENIPAl: Objetivos para o Desenvolvimento Sustentável das Naçōes Unidas:
como as bibliotecas podem contribuir com a implementaçào da Agenda 2030

Coimbra, n. 93. Quadrimestral. Disponível em: <http://rccs.revues.org/174>. Acesso em: 06 maio 2017.

ASSOCIAÇÃO BRASILEIRA DE NORMAS TÉCNICAS. NBR 9050: acessibilidade a edificações, mobiliário, espaços e equipamentos urbanos. 3. ed. Rio de Janeiro, 2015.

BRASIL. Decreto 3298 de 20 de dezembro de 1999. Dispõe sobre a Política Nacional para a Integração da Pessoa Portadora de Deficiência. Disponível em: <http://www.planalto.gov.br/ccivil 03/decreto/d3298.htm> . Acesso em: 03 maio 2017.

BRASIL. Lei no 13.146, de 6 de julho de 2015. Institui a Lei Brasileira de Inclusão da Pessoa com Deficiência (Estatuto da Pessoa com Deficiência). Diário Oficial da União, Brasília, DF, 7 jul. 2015. Disponível em:

<http://pesquisa.in.gov.br/imprensa/jsp/visualiza/index.jsp?data=07/07/2015\&jornal=1\&pagina =2\&totalArquivos=72>. Acesso em: 10 jun. 2017.

BRASIL. Secretaria Nacional de Promoção dos Direitos da Pessoa com Deficiência -

SNPD. Avanços das políticas públicas para as pessoas com deficiência: uma análise a partir das conferências nacionais. Brasília: Secretaria de Direitos Humanos, 2012. Disponivel em:

<http://www.pessoacomdeficiencia.gov.br/app/sites/default/files/publicacoes/livro-avancospoliticas-publicas-pcd.pdf>. Acesso em: 12 out. 2017.

BULOS, Uadi Lammêgo. Constituição Federal Anotada. 4. ed. São Paulo: Saraiva, 2007.

CHAUÍ, M. A universidade pública sob nova perspectiva. In: Conferência de abertura da 26 reunião anual da ANPED, Poços de Caldas, 5 de outubro de 2003.

DORNELES, Claunice Maria. A contribuição das novas tecnologias no processo de ensino e aprendizagem do deficiente visual. Campo Grande: Editora da UFMS, 2007.

DUDZIAK, E. A. Os faróis da sociedade de informação: uma análise crítica sobre a situação da competência em informação no Brasil. Inf. \& Soc., João Pessoa, v.18, n.2, p. 41-53, maio/ago. 2008. Disponível em: <http://www.ies.ufpb.br/ojs/index.php/ies/article/view/1704/2109>. Acesso em: 12 out. 2017.

IFLA - International Federation of Libraries Associations and Institutions. Acesso e oportunidade para todos: como as bibliotecas contribuem para a agenda de 2030 das Nações Unidas. Haia, Países Baixos, [2015?]. Disponível em:

<https://www.ifla.org/files/assets/hq/topics/libraries-development/documents/access-andopportunity-for-all-pt.pdf>. Acesso em: 12 out. 2017.

Declaração de Alexandria sobre competência Informacional e aprendizado ao longo da vida. In: National Fórum on Information Literacy, 2005. Disponível em:

<https://www.ifla.org/files/assets/wsis/Documents/beaconinfsoc-pt.pdf>. Acesso em 12 out. 2017. 

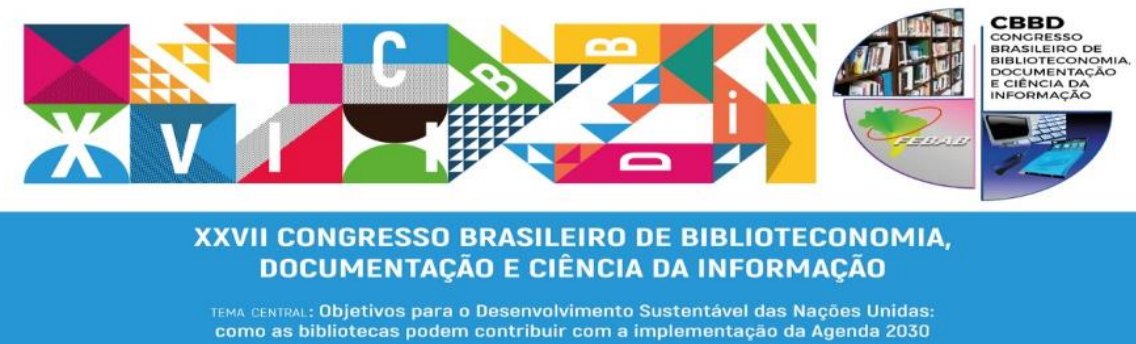

Las bibliotecas y la implementación de la Agenda 2030 de la ONU. IFLA: Haia, Países Baixos, 2015. Disponível em: <https://www.ifla.org/files/assets/hq/topics/librariesdevelopment/documents/libraries-un-2030-agenda-toolkit-es.pdf> . Acesso em: 12 out. 2017.

Lyon Declaration on Access to Information and Development. Haia, 2014. Disponível em:< http://www.lyondeclaration.org/content/pages/lyon-declaration.pdf $>$. Acesso em: 10 jul. 2017.

MANIFESTO de Florianópolis sobre a competência em informação e as populações vulneráveis e minorias. In: II SEMINÁRIO “COMPETÊNCIA EM INFORMAÇÃO: CENÁRIOS E TENDÊNCIAS”, 2013, Florianópolis. Disponível em:

<http://febab.org.br/manifesto florianopolis portugues.pdf>. Acesso em: 12 out. 2017.

NASCIMENTO, Francisco Paulo do Nascimento; SOUSA, Flávio Luís Leite. Metodologia da pesquisa científica teoria e prática: como elaborar TCC. 2. ed. Fortaleza: INESP, 2017.

ORGANIZAÇÃO DAS NAÇÕES UNIDAS (ONU). Transformando nosso mundo: a Agenda 2030. ONU: Nova Iorque, 2015. Disponível em:

<https://nacoesunidas.org/wp-content/uploads/2015/10/agenda2030-pt-br.pdf>. Acesso em: 26 abr. 2017.

PUPO, D. T.; MELO, A. M.; FERRES, S. P. Acessibilidade: discurso e prática no cotidiano das bibliotecas. Campinas: Unicamp, 2008. 1

SÉGUIN, E. Introdução. Raposa e ouriço. In: jurídica. Rio de Janeiro: Forense, 2002. p. 1-21. Minorias e grupos vulneráveis: uma abordagem

UNIVERSIDADE ESTADUAL DE CAMPINAS . Disponível em:

<http://www.todosnos.unicamp.br:8080/lab/>. Acesso em: 02 maio 2017.

UNIVERSIDADE FEDERAL DE MATO GROSSO DO SUL. Relatório de Gestão do exercício de 2016. Campo Grande, 2017.

UNIVERSIDADE FEDERAL DE SANTA CATARINA. Disponível em: < http://portal.bu.ufsc.br/conhecaa-bu/administrativo/estrutura-organizacional/dau/aai-acessibilidade/>. Acesso em: 02 maio 2017.

VIVARTA, Veet (coord.). Mídia e deficiência. Brasília: Andi, 2003. Disponível em:<http://www.andi.org.br/sites/default/files/Midia e deficiencia.pdf $>$. Acesso em: 07 de out.de 2017. 